University of Michigan Law School University of Michigan Law School Scholarship Repository

2017

\title{
The Effect of Criminal Records on Access to Employment
}

\author{
Amanda Agan \\ Rutgers University \\ Sonja B. Starr \\ University of Michigan Law School, sbstarr@umich.edu
}

Available at: https://repository.law.umich.edu/articles/1892

Follow this and additional works at: https://repository.law.umich.edu/articles

Part of the Civil Rights and Discrimination Commons, Law and Race Commons, Law and Society Commons, and the Law Enforcement and Corrections Commons

\section{Recommended Citation}

Agan, Amanda, co-author. "The Effect of Criminal Records on Access to Employment." Starr, Sonja B., co-author. Am. Econ. Rev.: Papers \& Proc. 107, no. 5 (2017): 560-64.

This Article is brought to you for free and open access by the Faculty Scholarship at University of Michigan Law School Scholarship Repository. It has been accepted for inclusion in Articles by an authorized administrator of University of Michigan Law School Scholarship Repository. For more information, please contact mlaw.repository@umich.edu. 


\title{
The Effect of Criminal Records on Access to Employment
}

\author{
By Amanda Agan and Sonja Stark*
}

In recent years, considerable policy attention has focused on the expansion of employment opportunities for people with criminal records. These efforts are motivated by the premisesupported by observational, survey, and experimental research-that applicants with records are disfavored by employers (see Schmitt and Warner 2010 for a review). Because the poor and minorities disproportionately have criminal records, these employment challenges may exacerbate existing socioeconomic and racial inequalities. Furthermore, job access for people with records can reduce criminal recidivism, potentially improving public safety (see, for example, Yelowitz and Bollinger 2015).

This paper adds to the empirical evidence regarding criminal records as a barrier to employment. We conducted a large-scale field experiment focused on the first stage of the employment process: employer callbacks in response to job applications. This is the stage in which most job applicants are filtered out. Moreover, the front end of the employment application process has been the focus of the most influential recent policy effort in this area: the Ban-the-Box (BTB) movement, which seeks to prevent employers from asking criminal-record-related questions (nicknamed "the box") on job applications and at interviews. The premise behind BTB is that front-end discrimination keeps many applicants with records from having a chance to impress employers with their qualifications.

Our experiment confirms this premise. The results presented in this paper are connected to

\footnotetext{
*Agan: Rutgers University, 75 Hamilton Street, New Brunswick, NJ 08901 (e-mail: aagan@econ.rutgers.edu); Starr: University of Michigan, 625 S. State Street, South Hall 3230, Ann Arbor, MI 48109 (e-mail: sbstarr@umich. edu). This experiment relied on a team of hardworking RAs and generous funding from Princeton University and the University of Michigan. Detailed acknowledgments are found in Agan and Starr (2016).

${ }^{\dagger}$ Go to https://doi.org/10.1257/aer.p20171003 to visit the article page for additional materials and author disclosure statement(s).
}

a larger project investigating BTB's effects on racial discrimination in New Jersey and New York City (Agan and Starr 2016). Here, we provide more detailed analysis of a subset of our data: applications from the pre-BTB period to employers that asked applicants about records (before it became illegal). Such employers were 60 percent more likely to call back applicants without records, even though the records we assigned applicants were minor (a single lowlevel, nonviolent felony approximately two years earlier). The criminal record effect is large in every subsample we investigate, regardless of the crime type (drug versus property) or other characteristics of applicants, employers, or neighborhoods. On the other hand, this effect is confined to employers that have the box-and even before BTB, the majority of employers in our larger experiment did not.

The core result presented here confirms that of past field experiments (Pager 2003; Pager, Western, and Bonikowski 2009; Uggen et al. 2014), but in a much larger and more recent sample, and a modality (online applications) that today dominates hiring in many industries. Moreover, we analyze the interaction of the criminal record effect with a variety of other variables not considered elsewhere - an analysis that confirms that effect's ubiquity.

\section{Method}

In our broader experiment, we sent nearly 15,000 online job applications to companies in New Jersey and New York City, before and after those jurisdictions implemented BTB laws in 2015. Agan and Starr (2016) provide methodological details, which we summarize briefly here. This paper focuses on the 2,655 pre-BTB applications sent to employers whose applications, at the time, asked about criminal records. This sample includes applications sent to 1,426 establishments belonging to 95 chains. We targeted entry-level jobs requiring no college education, mostly in restaurants and retail. 
Our fictitious applicants were men in their early 20s. Half were randomly assigned felony convictions, and of these, we randomized whether the conviction was for a drug or a property crime. All convictions were of similar legal severity, at the low end of felonies for the relevant jurisdiction-for example, small-scale larcenies or drug possession.

We also randomized other application characteristics; the potentially important distinctions were race (black and white), type of secondary diploma (regular high school versus GED), and whether there was a one-year gap between past employment stints (versus no gap). Other applicant characteristics (e.g., home address, past employers) were randomly selected among options designed to be substantively interchangeable while still disguising the similarity of applications.

The outcome variable assessed below is whether the applicant received a positive employer response (a "callback") via phone or e-mail within eight weeks. We assess whether callback rates vary by felony conviction status, and whether this record effect varies by other applicant, employer, or geographic characteristics.

\section{Results and Discussion}

\section{A. Effects of Felony Conviction Status on Employer Callback Rates}

In Table 1, we present the results of this study as simple summary statistics: callback rates for applicants with and without felony convictions, plus ratios and differences between the two. Because felony conviction status is randomized and uncorrelated with other applicant or job characteristics, regression-adjusted effect estimates are essentially identical to the raw differences, and we do not report them here. Table 1 also shows no significance tests, but additional regressions find that the conviction effect is statistically significant in every specification and subsample we analyzed ( $p$-values generally below 0.01 , with standard errors clustered on the employer chain) $\cdot 1$

\footnotetext{
${ }^{1}$ Regression analyses referred to in this discussion generally include key applicant characteristics (race, diploma type, and employment gap) as well as chain and locality fixed effects, except where the subsamples being discussed
}

In row 1 , we show the full sample results. Callback rates were 8.5 percent and 13.6 percent for applicants with and without convictions, respectively. That is, applicants without convictions received 60 percent more callbacks (5.1 percentage points). We report both ratios and differences because both may be of policy interest. In the subsample results below, similar differences do not always correspond to similar ratios (or vice versa), because overall callback rates vary among the subsamples.

In panel A, we continue to use the full sample, but we subdivide the reported callback rates for applicants with criminal records based on their crime type: property or drug crimes. (The no-conviction callback rate in both rows is thus the same as in row 1.) The callback rates are virtually identical for the two conviction types; employers treated both categories of crime equally adversely. This finding is contrary to our prior assumption. Although the crimes were all of similar severity, we expected that more stigma would attach to theft and similar convictions; avoiding employee theft is often cited as a motivation for background checks (Society for Human Resource Management 2012).

In panel $\mathrm{B}$, we subdivide the sample by race. The conviction effect is slightly larger for white applicants: 5.7 percentage points, versus 4.5 percentage points for black applicants. Although further regression analyses find that this interaction is not statistically significant, its direction is nonetheless interestingly contrary to Pager (2003, p. 959), who reports "nontrivial" (albeit also not statistically significant) evidence that "the effect of a criminal record appears more pronounced for blacks than for whites." Note that we also found almost no overall racial difference in callback rates, in contrast to most prior auditing studies. However, in Agan and Starr (2016), we find that among employers without the criminal record box (including these same employers after BTB), white applicants have a large advantage.

In panel C, we show separate results for New Jersey and New York City, respectively. In proportional terms, the criminal record effect is

are defined in a way (such as by race) to make particular variables inappropriate. These variables are discussed in more detail in Agan and Starr (2016). 
Table 1 -Callback Rates by Conviction Status

\begin{tabular}{|c|c|c|c|c|}
\hline & $\begin{array}{l}\text { No conviction } \\
\quad \text { (percent) }\end{array}$ & $\begin{array}{l}\text { Conviction } \\
\text { (percent) }\end{array}$ & Ratio & Difference \\
\hline Full sample $(n=2,655)$ & 13.6 & 8.5 & 1.60 & 5.1 \\
\hline \multicolumn{5}{|l|}{ Panel A. Crime type } \\
\hline $\operatorname{Drug}(n=1,952)$ & 13.6 & 8.5 & 1.59 & 5.0 \\
\hline Property $(n=2,022)$ & 13.6 & 8.4 & 1.62 & 5.2 \\
\hline \multicolumn{5}{|l|}{ Panel B. Applicant race } \\
\hline White $(n=1,348)$ & 14.0 & 8.3 & 1.69 & 5.7 \\
\hline Black $(n=1,307)$ & 13.1 & 8.6 & 1.52 & 4.5 \\
\hline \multicolumn{5}{|l|}{ Panel C. Jurisdiction } \\
\hline New Jersey $(n=1,037)$ & 16.4 & 11.3 & 1.45 & 5.1 \\
\hline New York City $(n=1,618)$ & 11.8 & 6.6 & 1.80 & 5.2 \\
\hline \multicolumn{5}{|l|}{ Panel D. Local crime } \\
\hline Above median $(n=1,328)$ & 13.1 & 8.4 & 1.55 & 4.6 \\
\hline Below median $(n=1,327)$ & 14.0 & 8.5 & 1.65 & 5.5 \\
\hline \multicolumn{5}{|c|}{ Panel E. Percent white, census block group } \\
\hline Above median $(n=1,327)$ & 16.1 & 9.3 & 1.74 & 6.9 \\
\hline Below median $(n=1,328)$ & 11.2 & 7.6 & 1.47 & 3.6 \\
\hline \multicolumn{5}{|l|}{ Panel F. Industry } \\
\hline Restaurants $(n=994)$ & 14.1 & 6.9 & 2.03 & 7.1 \\
\hline Retail $(n=1,496)$ & 12.7 & 8.7 & 1.45 & 3.9 \\
\hline
\end{tabular}

Notes: All applications were to employers whose applications asked about criminal records. Local crime refers to crime rates based on precinct-level data in New York City and town-level data in New Jersey.

substantially larger in New York City; indeed, even the difference is slightly larger there, despite much lower overall callback rates. In New York City, applicants without records received 80 percent more callbacks than those with records; in New Jersey this difference was 45 percent (still a large effect, to be sure).

The next two subsample comparisons assess more localized geographic differences. Panel D explores whether local crime rates affect employers' consideration of criminal records. One might expect, for example, that in higher-crime neighborhoods employers would be more familiar with and less averse to applicants with records; on the other hand, fear of crime might be higher in such neighborhoods. We linked employer addresses to reported crime data, which was available at the police precinct level in New York City and at the town level in New Jersey. ${ }^{2}$ We aggregated seven major

\footnotetext{
${ }^{2}$ Crime data come from public reports by police departments for 2015. The data for New Jersey are from the
}

reported crime categories that were common to both jurisdictions' reporting schemes (murder, felony assault, robbery, rape, burglary, grand larceny, motor vehicle larceny) and calculated total per capita crime rates, which we used to divide the sample into "high crime" (above median) and "low crime" halves.

The panel D comparison shows little difference between the conviction effects in high-crime and low-crime neighborhoods. We also conducted subsample analyses using

2015 Crime in the United States UCR report of Offenses Known to Law Enforcement by City (https://ucr.fbi.gov/ crime-in-the-u.s/2015/crime-in-the-u.s.-2015/tables/table-8/ table-8-state-pieces/table_8_offenses_known_to_law_ enforcement_new_jersey_by_city_2015.xls). New York City crime data are reported by precinct (http://www.nyc. gov/html/nypd/downloads/pdf/analysis_and_planning/ seven_major_felony_offenses_by_precinct_2000_2015. pdf). Because the New York City data were presented as totals and not per capita rates, we combined them with estimates of precinct populations from Infoshare Online (infoshare.org), which are based on GIS mapping of census data onto precinct boundaries. 
other crime-rate subdivisions (violent crimes and property crimes alone), plus full-sample regressions interacting the conviction effect with continuous versions of the crime-rate variables. None of these analyses indicated that local crime rates affect employers' treatment of criminal records.

However, panel E suggests some possible variation in the conviction effect by another local characteristic-neighborhood racial composition. We linked employer addresses to demographic data for the census block group, and divided the sample into neighborhoods with above- and below-median white population shares. In differences, the conviction effect was twice as large in the whiter neighborhoods. Whiter neighborhoods had higher callback rates overall, but the conviction effect was larger there even in proportional terms (a 74 percent higher callback rate for applicants without records, versus 47 percent in less white neighborhoods).

It is possible, for example, that fear of crime and/or stigma associated with criminal records could be greater among hiring managers or customers in whiter neighborhoods. Still, these differences are only suggestive. In regression analyses, the interaction between white population share and the conviction effect is statistically insignificant or, at best, marginally significant, depending on the specification. Moreover, the interaction between black population share and the conviction effect is not even consistent in sign across specifications. Other racial groups are quite large in these jurisdictions, so these analyses are far from mirror images.

Finally, in panel F, we show results separately for restaurant and retail employers, our two largest industry categories. These show a somewhat larger felony conviction effect among restaurants, in both differences and in proportional terms. However, in full-sample regressions with an industry interaction, this difference is statistically insignificant.

In sum, while there are some suggestive differences between subsamples, the adverse effect of having a felony conviction (even a fairly minor and nonviolent one) is quite large in every subsample we examined. When employers have access to criminal record information on job applications, they consistently appear to use it.

\section{B. Prevalence of the Criminal Record Box}

One factor that may mitigate the adverse effects of criminal records is that many employers do not ask about them on job applications. The box sample analyzed here represents 36 percent of the total set of applications we sent in the pre-BTB period of our larger experiment, and 32 percent of the chains. That is, most job postings that met our criteria were at employers that, even before BTB, chose not to ask about criminal records. While a few employers simply complied early before the effective dates of BTB in New York and/or New Jersey, most had no box at all on their national application platforms.

This observation was surprising, because earlier research has found otherwise. For example, Uggen et al. (2014), reporting on an experiment carried out in 2007 and 2008 that similarly targeted entry-level, low-skill positions, found that 80 percent of employers had the box. Although samples cannot be directly compared across different studies and cities, we suspect at least part of the difference reflects the recent success of the BTB movement (see Rodriguez and Avery 2016 for an overview). That movement has lobbied employers directly, plus the need to comply with an expanding list of state and local BTB laws may have persuaded national chains that it is easier to drop the box entirely.

Still, this potentially good news for applicants with records should not be overstated. An employer with no box on its initial application can find out about records later; even BTB only delays these inquiries, rather than barring them. Criminal record checks are ubiquitous (Society for Human Resource Management 2012).

It is possible that applicants with records will nonetheless be better off without the box; the assumption underlying BTB is that getting one's foot in the door matters. But it is also possible that criminal record effects similar to those we observed here could surface at non-box employers as well at other stages of the employment process. Testing this possibility would require research that goes beyond callbacks to assess hiring outcomes.

\section{Conclusion}

This study offers the largest-to-date field experiment testing the effect of criminal records on employment access. It confirms that even 
fairly minor felony records have large negative effects on employer callbacks across a variety of subsamples defined by applicant and job characteristics. The effect on labor market access may ultimately be limited by employers' voluntary or mandatory elimination of the criminal record box on job applications. Although the policy concerns associated with Ban-the-Box are complicated (Agan and Starr 2016 and Doleac and Hansen 2016 explore unintended racial consequences), our results here support its basic premise: when employers inquire about them, felony convictions reduce access to job opportunities.

\section{REFERENCES}

Agan, Amanda Y., and Sonja B. Starr. 2016. "Ban the Box, Criminal Records, and Statistical Discrimination: A Field Experiment." University of Michigan Law and Economics Research Paper 16-012.

Doleac, Jennifer, and Benjamin Hansen. 2016. "Does 'Ban the Box' Help or Hurt LowSkilled Workers? Statistical Discrimination and Employment Outcomes when Criminal Histories are Hidden" NBER Working Paper 22469.

-Pager, Devah. 2003. "The Mark of a Criminal
Record." American Journal of Sociology 108 (5): 937-75.

-Pager, Devah, Bruce Western, and Bart Bonikowski. 2009. "Discrimination in a Low-Wage Labor Market: A Field Experiment." American Sociological Review 74: 777-99.

Rodriguez, Michelle Natividad, and Beth Avery. 2016. Ban the Box: U.S. Cities, Counties, and States Adopt Fair-Chance Policies to Advance Employment Opportunities for People with Past Convictions. New York: National Employment Law Project.

Schmitt, John, and Kris Warner. 2010. Ex-Offenders and the Labor Market. Washington, DC: Center for Economic and Policy Research.

Society for Human Resource Management. 2012. The Use of Criminal Background Checks in Hiring Decisions. Alexandria: Society for Human Resource Management.

-Uggen, Christopher, Mike Vuolo, Sarah Lageson, Ebony Ruhland, and Hilary K. Whitham. 2014. "The Edge of Stigma: An Experimental Audit of the Effects of Low-Level Criminal Records on Employment." Criminology 52 (4): 627-54.

Yelowitz, Aaron, and Christopher Bollinger. 2015. "Prison-to-Work: The Benefits of Intensive Job-Search Assistance for Former Inmates." Manhattan Institute Civic Report 96. 